\title{
CARTOGRAFIANDO LA HISTORIA CONSTITUCIONAL
}

\section{A CARTOGRAPHY OF CONSTITUTIONAL HISTORY}

\author{
Sebastián Martín \\ Universidad de Sevilla
}

\begin{abstract}
Recensión de / Review of: Joaquín Varela Suanzes-Carpegna (ed.), Historia e historiografía constitucionales, Trotta, Madrid, 2015)
\end{abstract}

Palabras clave: historia constitucional, metodología historiográfica, historia global, historia del Estado.

Key words: constitutional history, historical method, global history, statebuilding.

Me atrevería a decir que el pequeño volumen aquí comentado es uno de esos títulos que pasarán a convertirse en indispensable lectura para quienes comienzan a cultivar, o deciden adentrarse por vez primera en la historia constitucional. También gozará de él el experto en las materias -derecho constitucional, historia del derecho, ciencia politica, historiografia política- en cuyo interior se han solido trabajar los objetos histórico-constitucionales. Y, naturalmente, compone un útil fresco de posiciones $\mathrm{y}$ sugerencias, tanto instrumentales como sustantivas, para quien se halla consagrado a este saber interdisciplinar.

En sus páginas se realizan múltiples referencias bibliográficas, quedan identificados numerosos dilemas metodológicos, se delimita desde varias perspectivas el perímetro de la disciplina analizada, se abocetan con eficacia diferentes tradiciones académicas nacionales, se dan a conocer trayectorias profesionales de primeros maestros, la experiencia intelectual española acerca de esta materia resulta desglosada con todo detalle, se realizan valiosas interpretaciones sobre aspectos centrales del objeto e incluso se localizan algunos de sus próximos desafios. Con todo este inventario de contenidos no puede sino suministrar al lector una eficiente brújula para orientarse en ese campo de la historia y la historiografia constitucionales, como su mismo título sugiere.

Que esta visión panorámica rica en matices sea posible en un volumen relativamente breve (apenas 160 páginas) lo explica su peculiar composición interna y su autoría coral. Aunque se trata de una iniciativa de Joaquín Varela, su editor, con una pieza capital de su discipulo, Ignacio Fernández Sarasola, ambos constitucionalistas ovetenses y responsables de buena parte de las empresas que sobre la materia se desarrollan en España, comenzando por la revista que acoge esta recensión, el libro cuenta con más autores, que entran en él en calidad de entrevistados. En efecto, parte central de este recorrido singular son las entrevistas que el profesor Varela ha venido realizando en los últimos años, para este medio, a algunos "maestros europeos" de la historiografía constitucional, como lo son Maurice J.C. Vile (Londres, 1927) Ernst-Wolfgang Böckenförde (Kassel, 1930), Michel Troper (París, 1938) y Maurizio Fioravanti (Prato, 1952), exponentes, respectivamente, de la academia británica y norteamericana, de la alemana, la francesa y la italiana, y representantes, 
también respectivamente, de las diferentes disciplinas desde las que la historia constitucional suele cultivarse, a saber, la ciencia politica, el derecho público, la filosofia jurídica, el derecho constitucional y la historia del derecho. Estas esclarecedoras conversaciones sobre el saber histórico-constitucional se ven flanqueadas, además, por un estudio metodológico suscrito por el propio editor, ya difundido en varias lenguas y debatido con anterioridad, pero actualizado para la ocasión, y por el citado ensayo conclusivo de Fernández Sarasola sobre la historiografia constitucional elaborada en España desde el arranque del constitucionalismo hasta nuestros días. Seis voces, cinco nacionalidades, cuatro disciplinas y el consiguiente entrecruce de una multiplicidad de perspectivas es, por tanto, lo mucho que este sucinto manual contiene.

La unidad de materia, la relativa homogeneidad de las cuestiones planteadas a los entrevistados y la clara visibilidad de ciertos hilos conductores confieren coherencia a un volumen marcado, en apariencia, por la heterogeneidad. Su organización interna, y la relativa autonomia de sus respectivas piezas, van a determinar la economía del presente comentario. Vamos, por tanto, a detenernos, en primer lugar, en las consideraciones metodológicas de Joaquín Varela, en segundo término, en el bloque de entrevistas, para seguidamente pasar a examinar cada una de ellas por separado, desembocando, en penúltimo lugar, en el examen del estudio de Ignacio Fernández Sarasola, terminando así con un balance conclusivo sobre esos hilos conductores recién citados, cuya reiterada aparición es la que logra ensamblar todos los componentes de esta exposición plural.

Dimensiones y dilemas metodológicos de la historia constitucional. Antes de comentar la contribución del editor, conviene facilitar una pista al lector. Algunas de sus intervenciones como entrevistador, junto al guión subyacente y a los puntos recurrentes, dan ocasión para profundizar, precisar o confirmar sus posiciones metodológicas ya expuestas en el capitulo inicial, por lo que conviene a veces integrar ambos extremos. Tal cosa sucede en puntos capitales, como cuando se extiende sobre las ideas de J.J. Park (pp. 69-70) o de Mortati (p. 97), o cuando alude a la necesidad de partir de un "concepto axiológico" de Constitución para elaborar la historia constitucional, algo que dejaría fuera de su campo de observación tanto a "los ordenamientos preliberales" como a los "antiliberales, ya sean de inspiración comunista o fascista", pues en ninguno de los casos existiría "división de poderes [...] con el objeto de asegurar las libertades individuales" (p. 53, y también pp. 99-102).

Uno de los méritos de la introducción metodológica del profesor Varela es que acompaña cada una de sus reflexiones teóricas de ejemplos, casos y referencias prácticas procedentes de su experiencia profesional. Leída en su dimensión aplicativa, emergen de ella corrientes de pensamiento, nombres de autores, sugerencias heurísticas y claves interpretativas, materiales que encierran, ya de por sí, una notoria utilidad. Nos interesa, de todos modos, abocetar la estructura de su ensayo, porque es ahí donde vamos a encontrar algunos de los hilos conductores que atraparán nuestra atención en la fase conclusiva. Podemos subdividir su ensayo preliminar en tres facetas: una, breve, dedicada a dar la definición y delimitación del campo disciplinar de la historia constitucional; otra, que sirve de nudo central, sobre las diferentes dimensiones que ha de abarcar la ciencia en cuestión; y una última, igualmente breve, pero también fundamental, que contiene algunos consejos metodológicos. 
Para Joaquín Varela la historia constitucional "se ocupa de la génesis y desarrollo de la Constitución del Estado liberal y liberal-democrático", teniendo, pues, como referente semántico fundamental, un "concepto sustantivo y axiológico de Constitución", entendido como "fenómeno histórico destinado a limitar el Estado al servicio de las libertades individuales" (p. 13). Con esta definición, y con las posteriores precisiones que aparecen en las entrevistas, resulta evidente que, desde su comprensión de la disciplina, quedan fuera de la misma tanto el llamado "constitucionalismo antiguo", aquel entramado de instituciones $\mathrm{y}$ valores, prácticas de poder $\mathrm{y}$ mentalidades, que forjaban $\mathrm{y}$ equilibraban jurídicamente la sociedad politica premoderna, como la experiencia de los totalitarismos de la Europa de entreguerras.

A pesar de estos descartes iniciales, para el arco cronológico que abarca, la propuesta disciplinar del editor podría calificarse de omnicomprensiva, por comprender todos los aspectos de relevancia histórico-constitucional, mas no de forma inconexa, sino con una evidente aspiración por integrarlos. Estos aspectos podrian reducirse básicamente a dos: uno institucional y otro cultural. Por lo que hace a la faceta "normativo-institucional", Varela distingue una dimensión estrictamente jurídico-positiva, que atiende al contenido más puramente normativo, y otra, más relevante, de naturaleza institucional, entendiendo, pues, que lo institucional no puede reducirse en ningún caso al examen de las normas que ponen en planta la institución, sino que cumple más bien atender a su desenvolvimiento efectivo y a las transformaciones que vaya experimentando. En tal sentido, aclara con tino que es "perfectamente coherente aceptar la validez del positivismo jurídico, incluso del normativismo kelseniano, en el ámbito de la Teoria General del Derecho y del Derecho Constitucional y reconocer a la vez su escaso o nulo valor para la Historia Constitucional" (p. 25, n. 24).

La dimensión institucional de la historia constitucional atiende entonces al proceso mismo de construcción del Estado, con su examen de la dinámica y posición concreta de cada institución constitucional. Es aquí, en su propósito de esclarecer el despliegue real del Estado, donde se le hace evidente que el derecho positivo escrito no basta en absoluto, debiendo acudirse igualmente al estudio de las "convenciones constitucionales o reglas no escritas", "esenciales para conocer el funcionamiento de [sus] instituciones básicas" (p. 15). Por otro lado, tales instituciones interesan por sí solas, pero también, de forma destacada, en función del grado de cumplimiento de los fines genuinos del constitucionalismo, por eso la historia constitucional ha de "interrogarse por su eficacia en la protección de los derechos fundamentales de los ciudadanos" (p. 18). En su aspecto institucional, la historia constitucional resulta de este modo situada en el entrecruce de dos campos íntimamente vinculados, el de la fundación y la acción de los poderes públicos y el de la salvaguarda de los derechos.

Sin embargo, su objeto, en la propuesta de Varela, no se ciñe a lo institucional, alcanzando asimismo lo "doctrinal", aspecto que en sus planteamientos conoce una ulterior bifurcación, la que distingue entre la historia de las corrientes del pensamiento jurídico-político y la historia de los conceptos y categorías constitucionales. Así, la historia constitucional, en esta segunda dimensión, es tanto historia cultural como historia conceptual. En el primer caso, sobresalen a su vez dos enfoques decisivos, el que estudia las doctrinas politicas en busca de "modelos constitucionales en liza" o de "tendencias constitucionales" (p. 21) y el que indaga en los procesos de "juridificación" que dichas doctrinas 
experimentaron a manos de los juristas sistemáticos y de la jurisprudencia, juridificación que también se puede observar en el caso de los conceptos políticoconstitucionales.

Como se ha adelantado, la apuesta del constitucionalista ovetense es integradora, no solo por aspirar a ensamblar estas piezas de carácter institucional y cultural, sino por querer presentarlas a su vez inscritas en sus contextos de referencia: el suministrado por la historia social, imprescindible para relacionar instituciones, doctrinas y conceptos "con la sociedad" de la que brotan (p. 17), pero también los proporcionados por la historia politica y por la historia científica e intelectual, útiles para situar, respectivamente, lo institucional y lo doctrinal (p. 21).

A este completo perfil del saber histórico-constitucional, acompaña el editor una serie de advertencias metodológicas dignas de tener en cuenta. El historiador del constitucionalismo debe evitar las interpretaciones teleológicas, provocadas por tomar como principio de una experiencia constitucional "el resultado final al que ha llegado", en vez de interesarse, como debería, por "su génesis y desarrollo" (p. 17). En íntima relación con ello, uno de los principales riesgos epistemológicos que entraña su labor es el del "presentismo", es decir, el de la proyección de categorias actuales sobre una experiencia pretérita, lo cual le hace incurrir en "anacronismos" y "anticipaciones". Como afirma el autor, es algo que suele ocurrir en el cultivo del aspecto cultural, sobre todo cuando es realizado por expertos en materia jurídica vigente, que sucumben con facilidad a la naturalización de las categorias fundamentales de su respectivo campo disciplinar, estando "a veces más atentos al estudio de un repertorio de ideas invariable a lo largo del tiempo, que a ver el tiempo de tales ideas, es decir, su historicidad" (p. 26). Por último, que el historiador del constitucionalismo aspire a conocer una experiencia constitucional pasada, desentrañando su propia gramática, no implica que su tarea deba hallarse huera de todo soporte hermenéutico y categorial. Una cosa es evitar proyecciones ilicitas desde la actualidad y otra muy distinta renunciar a las "categorias analíticas", por fuerza formales e instrumentales, que le permitirian desvelar mejor el sentido de la experiencia examinada, como acontece con los conceptos de "modelo constitucional" o de "principio estructural" (p. 28, n. 30), ambos empleados por el autor en algunos de sus estudios de historia constitucional comparada y nacional.

Un cuestionario para perfilar un saber. Al ensayo introductorio y metodológico del editor siguen, como se ha indicado, cuatro entrevistas. Sin perjuicio de su adaptación a cada diálogo particular, en todas ellas se aprecia un guión que adelanta los propósitos del editor/entrevistador. Precedidos de una breve semblanza bioprofesional y bibliográfica, los cuestionarios tratan de indagar en cuatro aspectos: la trayectoria intelectual de los entrevistados, la situación de la disciplina en su campo académico nacional, los dilemas metodológicos más acuciantes que han enfrentado en su labor investigadora y una breve prospectiva de la historia constitucional, tanto la realizada en su taller personal como la derivada del proceso de integración europea y de globalización mundial. Con las respuestas a estas cuestiones, a veces en exceso lacónicas, el lector termina teniendo, junto a unas relevantes autobiografias intelectuales, un buen repertorio de referencias temáticas y bibliográficas y una útil muestra de las disyuntivas metodológicas que a día de hoy instituyen el saber histórico-constitucional. 
Historiar "el fundamento politico-social de una época". La entrevista a ErnstWolfgang Böckenförde, cofundador de la Asociación Alemana de Historia Constitucional, es ocasión para conocer su trayectoria profesional, algunas genealogías en el terreno académico alemán, y la modesta situación que ocupa en él la historia constitucional, escasamente cultivada por juristas y en manos, principalmente, de historiadores. Concebida así como disciplina a caballo entre el derecho constitucional y la historiografia, el célebre profesor y magistrado alemán la entiende en referencia a un "concepto amplio de Constitución", donde quepa "la estructura y la evolución intelectual, política y social" y se toquen, por consiguiente, "cuestiones como las relativas a la forma en que está organizada la administración" o las atinentes a "las relaciones de la sociedad civil» (p. 36). Desde este punto de vista, la historia constitucional se dedicaría a reconstruir "el fundamento político-social de una época", resultando del todo insuficiente la versión que hace de ella un puro comentario de "los textos constitucionales" (p. 39).

Junto a esta noción de la materia, Böckenförde realiza también sugerencias metodológicas y prospectivas de relevancia. Matizando la útil advertencia del editor contra los 'presentismos', el lector verá en sus respuestas una paráfrasis de aquella sentencia de Croce a tenor de la cual la historia es siempre historia contemporánea porque, invariablemente, las preferencias investigadoras, los filtros intelectivos y los cánones para la interpretación los suministra siempre el presente del historiador. Se trata de un axioma metodológico que alcanzó elaborando su estudio doctoral sobre la historiografia constitucional alemana del siglo XIX, pero que puede elevarse desde luego a categoría general. Y en lo que hace a los planes de futuro, urge a la elaboración de una "Historia Constitucional comparada o europea", entendiendo que esta última, al revelar "las raíces comunes" tanto como las dispares singladuras, serviría de "condición del desarrollo conjunto de Europa en y a partir de sus Estados miembros y sus Naciones", pues con ella se "construye una conciencia conjunta" y se cultiva el sentimiento de pertenencia a una verdadera comunidad (p. 41). Será precisamente esta opinión la que permitirá al lector contrastar las diferentes prospectivas planteadas por los maestros entrevistados.

La historia constitucional como historia del discurso juridico. De mayor enjundia es la entrevista a Michel Troper. Entre las preguntas del profesor Varela y las respuestas del jurista parisino sale a flote un buen ramillete de títulos, autores y referencias con el que hacerse una composición de lugar bastante exacta de la historiografia constitucional en Francia ${ }^{1}$. Mérito de este segundo diálogo es además que aborde la cuestión de la historia reciente del derecho público en la academia francesa, marcado por la centralidad del derecho administrativo, por el relativo desinterés hacia el derecho constitucional y, hasta los años 70, por la colocación en su lugar de una suerte de sociología política, más preocupada por el estudio del ser de la política que de su deber ser. Al lector aficionado a la historia de los saberes juridicos, como lo es quien suscribe, interesa el dato por el claro paralelismo que arroja con el decurso del derecho público español, pero, a los efectos del asunto tratado en nuestro volumen, su

1 Destaca además la mención por Varela de una valiosa rareza de entreguerras, la Revue d'Histoire Politique et Constitutionnel (1937-1940), merecedora, si no lo tiene ya, de un estudio particular. 
mención importa porque deja traslucir cuál es el concepto que Troper maneja de historia constitucional.

En efecto, a su juicio, "si no había interés por el Derecho Constitucional [...] no habia apenas razones para interesarse por la Historia Constitucional, que era lo mismo pero en el pasado" (p. 50). ¿Y de qué se conforma ese derecho constitucional objeto presente y a la vez materia de historia? De discursos, argumentos, cultura, lenguaje. Al historiar constituciones, su contexto político de formación o los saberes jurídico-públicos que daban las claves para su intelección y articulación, el historiador del fenómeno constitucional tiene siempre ante sí "un modo de argumentación" (p. 49), discursos con su propia gramática e historicidad, los cuales conforman, en rigor, su objeto de estudio. La creencia, arraigada desde Carré de Malberg, de que tales principios, tras su consagración revolucionaria en la Francia de 1789, resultaban invariables, y el afán materialista de "describir hechos sociales reales" (ibíd.), bloquearon así por largo tiempo la elaboración de una auténtica historia constitucional, remplazada en numerosas ocasiones por una historia politica sin más. De hecho, según Troper, el "interés por la historia constitucional" se ha visto reavivado, entre otros motivos, por "la idea de una cultura jurídica formada históricamente, capaz de aclarar las estructuras del Derecho positivo contemporáneo" (p. 48), lo que, aplicado a nuestro caso, viene a significar que el auge de las investigaciones histórico-constitucionales, entre otras cosas, trae causa del estudio del constitucionalismo como cultura dotada de historicidad, atravesada por cesuras y mutaciones de sentido, cuyas categorias proporcionan y descifran los principios nucleares de los sistemas constitucionales.

Es aquí donde se aprecia una clave central de la propuesta disciplinar de Troper: la estrecha relación entablada entre la historia constitucional y el derecho constitucional, el especial servicio que aquélla debe prestar a éste. Si "la ciencia del Derecho Constitucional no tiene por objeto más que discursos", se impone entonces el conocimiento de "las condiciones de aparición de estos discursos" (p. 46), condiciones vinculadas, efectivamente, a la coyuntura histórica. Aplicando las sugerencias arqueológicas de Michel Foucault, la historia constitucional se centraria ante todo en las condiciones de emergencia de un discurso, en la disección del mismo en sus correspondientes enunciados y principios de distribución, y en la detección de las sucesivas inflexiones históricas que éstos, enunciados $\mathrm{y}$ principios distributivos, han ido experimentado. Así, lo fundamental es identificar el sentido que en cada experiencia han cobrado los postulados básicos del constitucionalismo, como la soberania, la representación o la separación de los poderes, teniendo presente que no cuentan con un significado apriorístico, dado para siempre de antemano, sino que es el "sistema constitucional" en que se integran, y las relaciones proporcionales establecidas entre sí, los que determinan su naturaleza. Esto explica que Troper, en sus clases de primer semestre de derecho constitucional, en lugar de impartir la entonces también en España- habitual teoría general del Estado enseñase historia constitucional, como ilustración práctica de los principios estatales en su desenvolvimiento histórico, aunque también, a mi modo de entender, como una utilísima demostración de que las bases del Estado de derecho no tienen nada de naturales, pues dependen de la historia.

Empleando la exposición introductoria de Joaquín Varela, diríase, pues, que para Troper la historia constitucional es, fundamentalmente, historia doctrinal y 
conceptual, mas no por rechazo a la historia de las instituciones políticas, sino por el convencimiento de que, aun cuando se estudian éstas, el historiador se las ve, en realidad, con los discursos y lenguajes que las representan, por lo que no deja de elaborar, en definitiva, historia cultural. Lo que sí parece excluido de su noción de la materia es aquella historia interesada en reconstruir "la realidad de los conflictos políticos del pasado", en describir las relaciones efectivas de poder, porque el objeto de la historia constitucional es otra realidad bien diversa y de carácter autónomo: la del discurso jurídico, realidad simbólica capaz, a su vez, de producir "efectos politicos y sociales" fundamentales (p. 49).

No se piense por ello que Troper aboga por una historia constitucional estrechamente juridicista, con desprecio hacia lo político. De hecho, llama la atención sobre lo "mal fundada" que suele encontrarse "la oposición político/jurídico". Por ejemplo, cuando se desprecia, como asunto jurídico y nada político, es decir, por irrelevante constitucionalmente, la cuestión de la función jurisdiccional, "tan política como la función legislativa o la administrativa" (p. 47). Como hace saber el editor/entrevistador, Troper, entre otras cosas, se distingue precisamente por la especial atención que ha prestado a la labor judicial como aspecto central de la historia constitucional, dedicación que no ha estado presidida, según se ha anotado, por una noción estrictamente formalista de la función judicial, sino por el convencimiento, muy francés y acertado, de su intenso alcance politico ${ }^{2}$.

Por tanto, la historia constitucional preconizada por el profesor parisino va más allá de una semántica histórica del discurso contenido en las normas constitucionales, en las doctrinas de los juristas y en los programas de los políticos. La exigencia de comprender el "entorno intelectual y social" y el "contexto argumentativo" (p. 53) en que se inscriben los conceptos constitucionales pasados amplía considerablemente su campo de observación. Un ejemplo claro de cómo sus investigaciones suponen un análisis refinado de la acción de los actores históricos lo da su monografía sobre la Constitución francesa de $1795^{3}$. En ella, según expresa en una de sus respuestas, sale a la luz cómo los "enunciados constitucionales" no son pura trasposición de las ideologías de sus autores, sino que éstos "producen y rehacen constantemente [sus] principios [...] a medida que argumentan e intentan mantener una coherencia entre lo que han hecho ya y lo que se disponen a hacer" (p. 47). Por tanto, el examen del discurso resulta en su caso indisociable del análisis de las acciones y estrategias de quienes lo formulan.

Al ser el objeto un discurso, el propio del constitucionalismo, e interesar tanto su composición y sentido internos en cada momento como sus efectos sobre la realidad, la disciplina resultante no puede excluir la investigación de los "sistemas antiliberales", tal y como propone Varela, pues los hubo en los que existió discursividad constitucional y en los que ésta encauzó algunos extremos de la vida política (p. 53). Si el asunto a tratar es principalmente discursivo, se entiende que las herramientas metodológicas que más aprecie Troper procedan ante todo de la filosofia del lenguaje y de la epistemología, campo, este último,

\footnotetext{
2 Como el propio Troper indica, se trata, por fortuna, de un asunto sobre el que se multiplican los trabajos. He aquí uno de los últimos ejemplos: Antonella Meniconi, Storia della magistratura italiana, Il Mulino, Bologna, 2013.

3 Michel Troper, Terminer la Révolution: la Constitution de 1795, Fayard, Paris, 2006.
} 
donde, por cierto, las autoridades francesas (Gaston Bachelard, Georges Canguilhem, el propio Foucault), son de primer orden. Y si la ciencia del derecho constitucional es al fin y al cabo un discurso, en el fondo no podía ser otra cosa la propia historiografia constitucional, que nada tiene de reflejo especular de lo que realmente aconteció en el pasado por ser toda ella un conjunto de enunciados organizados según una cierta disciplina argumentativa. Esto explica, a mi entender, que ante las preguntas sobre la pertinencia política de una historia constitucional europea, Troper, después de dudar acerca de lo que "significa precisamente esa dimensión europea de la Historia Constitucional", responda que este tipo de historiografia, si se propone demostrar la existencia de "una cultura jurídica común", "sería entonces una ideología más que una empresa científica" (p. 56). Y es que el objetivo político de construir una comunidad terminaría en este caso organizando el discurso históricoconstitucional, cuyas pautas de producción y distribución deberían responder, a juicio implícito de Troper, tan solo a intereses cognitivos.

Historia constitucional y prácticas del poder. La entrevista a Maurice J.C. Vice da también ocasión al lector para conocer, sobre todo por el juego de preguntas, un buen repertorio bibliográfico de la historiografia constitucional entre Gran Bretaña y los Estados Unidos. El maestro es en esta ocasión profesor de ciencia política, discípulo de Harold Laski y Karl Popper, y experto en el federalismo estadounidense, en la articulación del principio de la separación de poderes y, en general, en el sistema politico norteamericano. Su singular trayectoria y sus intereses científicos explican que la conversación se detenga en algunos momentos en consideraciones sobre el funcionamiento del orden constitucional británico (p. 71) o de los Estados Unidos, e incluso en referencias de crítica política actual. A mi juicio, cuentan con especial valor estos últimos pasajes, no solo porque sean una excepción en el curso del libro, sino por el contenido mismo de las críticas, muy atinadas y previsoras, como lo es su censura al predominio del ejecutivo en Gran Bretaña consumado en la "era Blair" (p. 64) o su advertencia sobre las crecientes "divisiones étnicas en la política norteamericana" (p. 65).

Ya este buen olfato para las cuestiones de política práctica sugiere su concepto de la historia constitucional. Desde luego, no se trata del "mero hecho de contar una Constitución". Lo crucial es atender a la "distribución del poder político y [a] la forma en que éste se ejerce", algo en lo que entran en juego "las disposiciones constitucionales" (p. 60), pero también las instituciones y la cultura políticas que permiten que éstas se apliquen, así como los grupos de presión y los partidos. El dato es que para esclarecer la distribución del poder y el modo en que éste se ejerce no basta con conocer la regulación constitucional o la cultura que le da sustento. Deben además por fuerza estudiarse las mismas luchas por el poder y por su conservación, y las prácticas que canalizan su desenvolvimiento efectivo. Del contenido que habría de tener una historia constitucional asi concebida da un valiosísimo ejemplo, en uno de los fragmentos más decisivos de todo el libro, cuando explica su visión de la revolución norteamericana. En efecto, preguntado por el profesor Varela acerca de las interpretaciones que sobre la misma formularon Bernard Baylin, entendiéndola como "lucha ideológica", o Nicola Matteucci, concibiéndola como gesta constitucional, Vice da todo un quiebro de registro exponiendo las razones e intereses materiales de los colonos revolucionarios, aclarando que su propósito "no fue transformar la sociedad 
norteamericana, sino tomar el control del poder colonial mientras mantenían las relaciones de poder existentes dentro de las colonias", "desmontando con rapidez cualquier movimiento popular democrático que trató de emerger" (pp. 68-69). Conviene retener este contraste, el abierto entre las habituales lecturas intelectuales o apologéticas y los acercamientos que se centran en el interés material de los actores y sus luchas por el poder, porque habrá de prestar base a algunas de las reflexiones finales. Por lo pronto, el lector puede apreciar la viva tensión abierta entre la noción pragmática sostenida por Vice y la discursiva y cultural de Troper, que renuncia de entrada a la posibilidad de conocer las motivaciones materiales de los agentes históricos.

Antes de continuar abundando en el particular, cumple concluir el comentario a esta tercera entrevista. Caracterizada la visión de Vice, en expresión del entrevistador, por la "mixtura de política y derecho" (p. 76), su concepción de la disciplina se halla vinculada al propósito más general de entender "la naturaleza de la política", para lo cual es indispensable, en su opinión, interconectar "comportamientos, instituciones e ideas" (p. 75). Y si el nudo de sus preocupaciones radica en la lucha por el poder, el modo de distribuirlo y la forma de ejercerlo, las inquietudes metodológicas no podían sino referirse a la complicada "asignación de motivos a los actores políticos" (p. 67), al esclarecimiento de los siempre complejos y contradictorios móviles de la acción social.

Por último, en el diálogo sobre la prospectiva de la disciplina, centrándose en esta ocasión en un ámbito no exclusivamente europeo, dada la relevancia americana, salta un tema capital a día de hoy, el del constitucionalismo en América Latina. En una significativa rectificación de su posición anterior, Vice lanza al respecto la acertada intuición de que dicho constitucionalismo conforma un modelo propio, distinguido del "estilo occidental», aunque su posible peculiaridad la sigue midiendo en negativo, utilizando como indicadores los proporcionados por el tipo de "democracia occidental" (pp. 81-82), en lugar de apuntar las peculiaridades inmanentes que lo diferencian, bien visibles en el aspecto nacional o en el propio capítulo, fundamental, de los derechos ${ }^{4}$. Hubiera sido buena ocasión para que el entrevistador, interrogado por una vez por uno de sus entrevistados -"estaría muy interesado en conocer su propia perspectiva", le interpela Vice-, se hubiese explayado sobre asunto de tan primordial interés, aunque bien es verdad que el formato de cuestionario enviado por escrito para su respuesta lo dificultaba.

En busca de los modelos del constitucionalismo. Para quien comparte numerosas directrices metodológicas y preferencias temáticas con la escuela florentina de historia del pensamiento jurídico, para quien además comenzó a formarse como historiador del derecho con la lectura y estudio de Los derechos fundamentales: apuntes sobre historia de las constituciones, la entrevista a su autor, el profesor Maurizio Fioravanti, es motivo de gratificante estímulo intelectual. Más aún vista la extensión que en ella ocupa la exposición de su semblanza académica y profesional, desde la asistencia a las clases límpidas de

\footnotetext{
4 En este sentido apuntan algunas intervenciones de Bartolomé Clavero: «Estado plurinacional: aproximación a un nuevo paradigma constitucional americano", en Adriana Luna-Fabritius, Pablo Mijangos González y Rafael Rojas Gutiérrez (coords.), De Cádiz al siglo XXI. Doscientos años de constitucionalismo en México e Hispanoamérica (1812-2012), Taurus, Madrid, 2012.
} 
Paolo Grossi hasta las posteriores estancias alemanas o el contacto ulterior con el instituto trentino dirigido por Piarengelo Schiera. El lector encontrará también en esta conversación, como siempre, útiles referencias bibliográficas, está vez en menor cantidad, reflexiones e indicaciones acerca del estatuto, posición y cultivo de la historia constitucional en la investigación y la docencia italianas, y consideraciones reveladoras sobre la perspectiva del propio autor, como, por ejemplo, su actitud crítica con la obra de Matteuci y el propósito originario que sus Appunti tuvieron de sustituir para la formación del jurista el conocido libro de aquél, titulado Organizzazione del potere e libertà.

Interesa a nuestro comentario, a fin de comparar con los otros "maestros europeos", identificar cuál es la noción de historia constitucional mantenida por Fioravanti. Aclara, ante todo, lo que, a su juicio, no lo es en absoluto: una pura historia lineal de las constituciones y de "la legislación en materia constitucional", que prescinda de los "fundamentos histórico-constitucionales" (p. 100). Por tanto, pese a la complicada tarea de definir este saber, e insistiendo en que no puede reducirse en ningún caso a "simple historia de las constituciones en sentido formal" (p. 89), apuesta por concebirla como un "campo de acción" multidisciplinar, cultivado por la historia del derecho, el derecho constitucional y las ciencias políticas, y ocupado tanto de las doctrinas como de las constituciones. Llama, en efecto, la atención la coincidencia a este respecto con Varela. También por entender que no cabe disociar ambos polos, el cultural y el normativo-institucional. Así es: para Fioravanti, la historia constitucional, en tanto que "historia de la formación de la ley fundamental en una concreta colectividad", debe ser "historia de la cultura constitucional y al mismo tiempo historia de las prácticas, de las reglas, de las tutelas" (p. 97). Y aunque reconoce su abierta preferencia por el aspecto conceptual, señala expresamente que ambos extremos, el cultural y el que atiende a la experiencia, no deben ignorarse.

Volvemos, pues, a colocarnos ante un concepto amplio de la historia constitucional. En este caso lo inspira una noción "no dogmática" del constitucionalismo, entendido ante todo como "construcción del principio de unidad política", como existencia y vigencia socialmente consentida de una "lex fundamentalis" (p. 101), con una dimensión cultural esencial y un desenvolvimiento institucional no menos capital. Esta concepción extensiva es el motivo por el que Fioravanti se separa de la delimitación restrictiva planteada por Varela, sosteniendo que a la historia constitucional interesa tanto la experiencia del constitucionalismo antiguo como también la articulación política de los fascismos.

Mostrando una seña de identidad de la escuela de Paolo Grossi, para Fioravanti una de las misiones cientificas de la historia constitucional es la de "realizar el llamado 'coloquio' entre historiadores del derecho y juristas del derecho positivo" (p. 96), en este caso, los dogmáticos del derecho constitucional. Cabe indicar que se trata de un diálogo en provecho mutuo: los juristas dedicados al derecho vigente suelen movilizar un arsenal de categorías, conceptos y preocupaciones que deben guiar las prospecciones del historiador, las cuales, a su vez, revelan al dogmático la historicidad esencial del discurso que él se encarga de formar y reproducir. En cuanto a la docencia, para Fioravanti, la función de la historia constitucional ha variado considerablemente. Este punto es de relevancia capital. Si en un principio pudo concebir la materia como "exposición de los 'precedentes'” del derecho constitucional en vigor, en la 
actualidad la entiende "como parte integrante de la interpretación constitucional, esto es, del trabajo que los juristas realizan a través de la doctrina y la jurisprudencia para dotar de significado a las normas de la Constitución", pues en esa labor interpretativa suelen aplicarse criterios histórico-culturales (p. 99). Enseñar, pues, historia constitucional, se revela como un modo preliminar y esencial para impartir el propio derecho constitucional.

Esta importancia conferida a la interpretación nos pone ante una de las inquietudes más recientes del maestro florentino. Y también ante su forma inconfundible de trabajar, que recuerda a las sugerencias metodológicas de Max Weber, autor que conoce a fondo. Elabora Fioravanti la historia constitucional como reconstrucción de los conceptos y fundamentos del constitucionalismo, agrupándolos en modelos o tipos coherentes, que sirven para comprender mejor una experiencia constitucional concreta. Ese es, efectivamente, el método expositivo empleado en sus Appunti, a cuyos tres grandes modelos (individualista, historicista, estatalista) continúa confiriéndo plena validez. Pero se hacía referencia a una de sus últimas preferencias investigadoras: la recomposición, justamente, de otro "tipo históricamente determinado de Constitución", que jalona la última "etapa" de "la historia del constitucionalismo", a saber, la "Constitución democrática del siglo XX", la democracia constitucional nacida en Weimar y todavía en pie hoy por Europa, aunque cada vez más periclitada (p. 96) ${ }^{5}$. Por eso, a su juicio, es tarea decisiva de la disciplina cultivar lo que Varela llama la "Historia constitucional del tiempo presente" (p. 102).

Siendo un rasgo distintivo de este último tipo histórico de constitucionalismo el contener "normas fundamentales de principio, en particular en el campo de los derechos fundamentales" (p. 98), que deben ser concretadas mediante la interpretación y ponderación jurisprudencial, su reconstrucción pone frente al investigador un campo de indagación historiográfica fundamental, el de la "jurisdicción": "el tema que más apasiona" al entrevistado (p. 91) y que estima central para el propio futuro de la integración europea (p. 105). Y como al fin y al cabo la jurisprudencia, en su labor de "concreción de las normas constitucionales de principio", emplea en muchos casos criterios de carácter "histórico-cultural", esa es la razón, como antes se indicó, por la que la historia constitucional, tanto en la formación jurídica como en el diálogo con los juristas positivos, pasa a desempeñar un papel fundamental, no solo de ilustración externa, sino de suministro de criterios profesionales prácticos. Es más, la historia constitucional, en esta tarea central de mostrar el "tipo histórico común" de "la democracia constitucional europea" no solo estaria jugando un papel decisivo desde el punto de vista jurídico, sino también desde el político, al prevenirnos contra los recientes "atajos de carácter neonacionalista" (p. 104).

Por lo que alcanzo a saber, sus últimas investigaciones continúan además en esta línea de reconstrucción de modelos del constitucionalismo, deteniéndose esta vez en las experiencias bajomedievales plasmadas en documentos como la Carta Magna, pero también el Privilegio de Aragón o las Bulas de Oro alemanas.

5 Se trata de un asunto abordado en su Constitucionalismo. Experiencias históricas y tendencias actuales, Trotta, Madrid, 2014, pp. 99-103 y 120-127. 
Halla en ellos Fioravanti un particular modo de concebir y articular "el principio de unidad politica", que titula como government of the land ${ }^{6}$.

Es aquí, en la labor de reconstrucción de los modelos del constitucionalismo, donde el propio Fioravanti reconoce una de sus carencias. No es, desde luego, la comparación, que realizó desde joven hallando la clave de diferenciación entre el modelo europeo y el norteamericano en los derechos sociales; tampoco la historia constitucional europea, que también él, como Böckenförde, considera una aportación valiosa, en sentido ciudadano, para el proyecto constituyente europeo. Es un vacío que le indica Varela: el de otro tipo histórico de constitucionalismo, precisamente el hispánico, decisivo entre Europa y América, y que no encaja bien, por su tradicionalismo y su catolicismo, en los modelos que ha ido acuñando. "Esta es laguna que debe ser absolutamente colmada" (p. 108), concluye con razón Fioravanti, aunque se encuentra ya bastante cubierta por alguna historiografia constitucional española, que basta con manejar y consultar.

España, la bibliografía histórico-constitucional ante las encrucijadas politicas y estado actual de la disciplina. El volumen que estamos recorriendo concluye con un exhaustivo estudio, suscrito por Ignacio Fernández Sarasola, sobre la historiografia constitucional cultivada en España desde el arranque del siglo XIX. Comprende dos bloques, cuyo gozne es precisamente la Transición y el sistema constitucional de 1978. Y lo alienta una acertada conclusión: que "la historia constitucional nacional tiende a revitalizarse cuando un país se ve inmerso en procesos constituyentes o de reforma constitucional» (p. 133).

El primer bloque comienza con las reflexiones que leyeron el pasado medieval castellano en clave constitucional, repasa las principales obras sobre la historia política de la España liberal, comenta las investigaciones monográficas fundamentales, dedicadas principalmente a los origenes del constitucionalismo, y acude a los tratados de derecho politico como fuente destacada de la historia constitucional, afirmando, con razón, que Adolfo Posada, el maestro general de la materia, "convertiria la historia constitucional en un saber imprescindible para la formación" del constitucionalista (p. 121). Comienza después el análisis del largo periodo franquista, atravesado por un inicio antiliberal que hizo despreciar a los autores todo contenido histórico-constitucional. De este intervalo le interesan, ante todo, dos contrastes y varias fuentes: el primer contraste lo da la contraposición entre la feliz y decisiva obra (liberal) de Miguel Artola y la menos original y más reiterativa en sus fundamentos (conservadores) de Federico Suárez; el segundo, ya colocado en el marco de la "historia constitucional de conjunto", lo conforma la relación complementaria existente entre las dos exposiciones generales del régimen, la de Luis Sánchez Agesta (1955), marcada por su "claro juicio de valor negativo sobre la historia constitucional española" (p. 127), y la posterior de Joaquín Tomás Villarroya (1975), dedicada principalmente al "análisis normativo" (p. 132). Y las fuentes que exhuma van de recopilaciones documentales y normativas (Diaz Plaja, Diego Sevilla, Enrique Tierno) a monográficos y ensayos de la Revista de Estudios Politicos, buena parte de los cuales circuló cuando, por revisiones internas del franquismo, lo constitucional ya no era demonizado.

6 Extracto el planteamiento de una conversación personal que mantuve con el propio Fioravanti el 20 de mayo en Florencia, a cuenta de su intervención en este evento conmemorativo: http://ukconstitutionallaw.org/2015/05/12/event-the-constitutional-heritage-of-magna-carta/ 
Mérito de esta reconstrucción es, desde luego, su formidable acopio documental, que apenas deja fleco por tocar. A quien suscribe estas lineas, le ha descubierto numerosos autores y textos de interés (el Derecho parlamentario español de Manuel Fernández Martín, el Tratado de derecho politico de Ricardo Rovira, algún libro de Jerónimo Bécker, la Pugna entre dos poderes de Cánovas Cervantes o la tesis doctoral de Fernando Jiménez de Gregorio). A buen seguro le ocurrirá lo mismo al lector que la consulte. Por otra parte, la cumplida y sucinta exposición de contenidos, y la correcta colocación política, doctrinal e histórica de los autores y obras examinados, permite una eficaz orientación en el terreno analizado. Quizá podría haberse dejado más espacio a la crítica (merecida) de las citadas exposiciones de conjunto, pero es en todo caso una opción personal del autor el no haberse centrado en ella.

Sí existe dicha ponderación crítica en una parte del segundo bloque, que abarca desde la Transición a la actualidad. La tesis de fondo del mismo es que, una vez estabilizado el sistema del '78, el propósito político habitual de la historia constitucional, siempre preponderante en los trances constituyentes, cedió su espacio a "un interés netamente científico" (p. 134). Con este fin cognitivo más que performativo se han aproximado a la historia constitucional ante todo tres disciplinas: la historia contemporánea, el derecho constitucional y la historia del derecho. Y es aquí donde se pueden apreciar las críticas. Reducido el derecho constitucional tras la norma fundamental de 1978 a dogmática jurídico-positiva e interpretación jurisprudencial, cuando "vuelve la mirada al pasado" suele incurrir en "presentismos", conectando, "sin reflexión suficiente", instituciones pasadas con figuras vigentes elevándolas a la categoría de precedente (p. 137). Por su parte, la historia del derecho, muy "tardiamente" ocupada de la disciplina, y habitualmente afanada en el estudio de la sociedad premoderna, adoleceria, a juicio de Fernández Sarasola, de un defecto inverso, el de proyectar "la historia constitucional hacia el Antiguo Régimen", algo que le permite "con mayor facilidad determinar los elementos de continuidad" (p. 135), pero también le hace no reparar a veces en las aportaciones novedosas y genuinas del constitucionalismo temprano. Cabría añadir a todo ello que, aun habiéndose arrinconado la función politica de la historia constitucional, la posición ideológica de los autores que la han cultivado ha continuado, de un modo $u$ otro, y en todos los casos, siendo determinante. Puede, además, que la nueva coyuntura crítica que atravesamos, en la cual reverdece el reformismo y hasta el espíritu constituyente, esté ya invitando a mirar a nuestro pasado constitucional, sobre todo al más reciente, en busca de respuestas a nuestros padecimientos.

$\mathrm{Su}$ estudio prosigue con un estado de la situación actual de la materia, donde expone los proyectos y las iniciativas, las colecciones y empresas académicas que a día de hoy impulsan su elaboración. Aunque su trazado es completo, permítaseme en algunos puntos el mero complemento. Comienza justamente mencionando el proyecto HICOES, dirigido por Bartolomé Clavero y Marta Lorente, y del que destaca, con acierto, su especial dedicación al constitucionalismo gaditano y a la historia de la justicia ${ }^{7}$, aunque quizá convenga

\footnotetext{
7 Las posiciones de este grupo de investigación en la materia, mejor que en la Historia legal de la justicia en España (1810-1978), Iustel, Madrid, 2012, introducida y cuidada por Marta Lorente, Julia Solla y Fernando Martínez, quedan plasmadas en el volumen dirigido por la propia Lorente bajo el título De justicia de jueces a justicia de leyes: hacia la España de 1870, CGPJ, Madrid, 2007.
} 
añadir también los estudios de la prematuramente difunta Carmen Muñoz de Bustillo sobre Bayona ${ }^{8}$, las decisivas investigaciones de Marta Lorente sobre el periodo isabelino ${ }^{9}$, la tesis doctoral de Carmen Serván acerca del Sexenio ${ }^{10}$ y un reciente examen del propio Clavero sobre aspectos centrales de la Transición ${ }^{11}$. Prosigue con el decisivo proyecto de historia conceptual liderado por Javier Fernández Sebastián, inscrito en el importante grupo de investigación Iberconceptos, que con sus tres diccionarios ha dado todo un espaldarazo a la historia de los conceptos políticos en España. Y menciona igualmente, por afectar al caso español, el ambicioso proyecto de historia constitucional comparada de Horst Dippel, apartado en el que quizá cabria incluir también el portentoso Handbuch der europäischen Verfassungsgeschichte dirigido por Peter Brandt, Martin Kirsch y Arthur Schlegelmilch, del que ya han salido sus dos primeras entregas.

Se ocupa después de las ediciones de documentos constitucionales: de la recopilación de Raquel Rico o la colección de constituciones dirigida por Miguel Artola a la reciente serie, publicada asimismo por la editorial Iustel, sobre Leyes Politicas Españolas concebida por Joaquín Varela. Menciona las numerosas ediciones de clásicos del pensamiento jurídico-político español, empresa en la que destaca ante todo la intervención del Centro de Estudios Políticos y Constitucionales ${ }^{12}$. Por último, refiere iniciativas académicas, como el concurrido Seminario de Historia Constitucional Martinez Marina creado por Joaquín Varela, congresos, como los últimamente celebrados con motivo del bicentenario doceañista, y revistas, como la que aloja este comentario, la más importante en la materia en la academia española, con "más de mil doscientas visitas diarias" (p. 150).

De todo este recorrido, solo sabe demasiado a poco el espacio dejado al análisis de los manuales en circulación de historia constitucional, que habría estado bien describir, criticar, situar y comparar. De haber sido así, podrían haberse planteado interrogantes de interés para la propia historia constitucional española, como la función que desempeñó en nuestro último periodo

$8 \mathrm{Su}$ tesis Bayona en Andalucía. El Estado bonapartista en la prefectura de Xerez, CEC, Madrid, 1991, aunque también ensayos posteriores, como "La fallida recepción en España de la justicia napoleónica (1808-1810)", contenido en el citado volumen De justicia de jueces a justicia de leyes, pp. 135-168, que colman siquiera en parte la indiferencia que el autor atribuye al grupo -al que pertenezco- hacia el asunto de Bayona. Quizá la laguna proceda más bien de no haberse ocupado lo suficiente, no de los orígenes franceses, sino de los periodos posteriores al Sexenio, carencia de todos modos próxima a subsanarse a través de su último proyecto concedido, que ya llega a estos extremos.

9 Baste citar uno de los más decisivos: La voz del Estado. La publicación de las normas (18101889), CEC-BOE, Madrid, 2001.

10 Laboratorio constitucional en España: el individuo y el ordenamiento (1868-1873), CEPC, Madrid, 2005.

${ }^{11}$ España, 1978: la amnesia constituyente, Marcial Pons, Madrid, 2014.

12 Me tomo en este punto la licencia de referir la reciente aparición de otra colección, codirigida por el constitucionalista Víctor J. Vázquez y por quien suscribe, sobre Clásicos e inéditos del derecho público español, publicada por la editorial sevillana Athenaica y en la que ya han visto la luz el Derecho politico comparado de Laureano Figuerola, el Derecho internacional público de Rafael Conde Luque y el Derecho político de Eduardo Soler, y en la que saldrán textos de Manuel Pedroso, Ignacio Lojendio o Francisco Ayala, entre otros. 
constituyente el relato contenido en exposiciones generales como la de Jordi Solé Tura y Eliseo Aja, publicada en 1978, o la imagen resultante de la difundida presentación del constitucionalismo histórico español suscrita por Jorge de Esteban. Lo que si es bien cierto es que la existencia de estos manuales, o la publicación reciente de aproximaciones fragmentarias más completas, no ha cubierto aún la "necesidad de que se elabore un estudio que aborde nuestra historia constitucional con rigor y en conjunto", incluyendo los aspectos normativo, doctrinal e institucional, y sin descuidar la perspectiva comparada. Desde luego, se ha acumulado en España ya suficiente acervo investigador, y se ha alcanzado tal riqueza, complejidad y variedad de perspectivas en materia histórico-constitucional, que, como Fernández Sarasola concluye, es momento para que "se transite ya" de "los incontables estudios parciales a una visión de conjunto" (p. 152) ${ }^{13}$.

Historia del Estado, historia del poder, historia juridica global. Cumple, para finalizar esta revisión, realizar un somero balance conclusivo. El protagonista de estas lineas es, sin duda, el volumen comentado, y no las ideas que sobre la materia tiene su autor. Pero permitaseme lanzar algunas consideraciones al hilo del libro recensionado. De toda nuestra síntesis ha salido una idea clara: la historia constitucional no puede ser una exegética de las constituciones pretéritas. Es, debe ser, mucho más, y por desgracia, entre nosotros, no lo ha sido del todo todavía, al menos en lo que hace a las exposiciones generales. Si su hilo conductor trasciende la sucesión de códigos fundamentales, no pueden ser éstos los que sirvan para dosificarla en periodos delimitados. Algo hay, en efecto, que los trasciende.

Del repaso ha salido también una polémica, la referida a la delimitación de su objeto y cronología. Para Joaquín Varela deben excluirse el constitucionalismo antiguo y los fascismos, para Troper, en cambio, estos últimos, por contar algunos con dinámica constitucional, entran en el campo de observación, y para Fioravanti, atento al principio de unificación política, interesan tanto el constitucionalismo antiguo como el modelo totalitario. Si el objeto no es primordialmente la letra de la constitución, sino la organización del Estado, su dinámica institucional, y sus respectivos fundamentos culturales, acaso quepa considerar como un objeto más remoto la sociedad de órdenes, estamentos y corporaciones, aunque ya en ella existe un principio distributivo del poder y una concepción de los derechos y libertades, que aconseja incluirla. Algunas experiencias fascistas, como la del Estado Novo portugués, contaron con Constitución, la corporativa de 1933, que obligan, de hecho, a considerarlo. Partir de un concepto apriorístico de Constitución, que sirva de referencia para distinguir lo que entra dentro y lo que debe excluirse de la observación, resta más que suma a la historia constitucional, aunque dicho concepto "axiológico" pueda servir, no tanto para descartar el análisis de ciertos sistemas cuanto para valorarlos desde el punto de vista político, como negación de ese espíritu constitucional que se tiene por primordial.

El problema de ese concepto adoptado de antemano, procedente de la Declaración francesa de 1789 , es que ni siquiera se ve satisfactoriamente

13 Por las noticias que tengo, prepara precisamente el profesor Varela una Historia constitucional de España, aplicando sus reglas metodológicas y su concepto de la disciplina, que saldrá el próximo año en la casa Marcial Pons. 
cumplido por un siglo XIX europeo donde con dificultad puede hablarse de separación de poderes y protección de los derechos, no solo por el doctrinarismo de muchas constituciones, sino incluso por su precaria vigencia en la práctica. E1 posterior decurso histórico-constitucional, el de los Estados sociales y democráticos de entreguerras, aunque encaje en términos genéricos en el molde, también confrontaba abiertamente con el tipo originario. Y excluir, por último, a los fascismos, impide apreciar algo capital, y habitualmente desatendido, como son las continuidades inconfesables entre el Estado liberal oligárquico y los sistemas totalitarios. Lo evidente, desde luego, es que si entra el constitucionalismo antiguo $\mathrm{y}$, sobre todo, si se atiende a las experiencias dictatoriales, es porque la historia constitucional ha dejado de considerarse una suerte de historia de la libertad en singular. Pero, en ese caso, ¿a qué es a lo que atiende en realidad?

Y, en primer término, ¿cómo se hace? De la exposición puede inferirse otro acuerdo: propio de la historia constitucional es tanto lo jurídico-positivo y lo institucional como lo cultural. El método para encarar todo ello no queda, sin embargo, consensuado. Salvo Troper, más preciso en este plano, el resto de intervenciones o han advertido riesgos y dificultades, o solo han mencionado de pasada algunos desafios, o han dado la metodologia por descontada o no han vislumbrado especial dificultad metodológica a la hora de historiar pensamiento, instituciones, normas y acción político-social. Quizá sea señal de que, en cuestión de método, no hay nada mejor que hacer camino al andar. La mirada investigadora carente de reflexión metodológica produce siempre parcos resultados, pero la que se halla saturada de ella a veces recrea más el método amado que el objeto analizado. De hecho, en las ciencias sociales, el método correcto lo dicta siempre el objeto. No existe, a priori, metodología universal fructifera. Es preferible el pragmatismo. Por eso atender a un objeto multidimensional como la historia constitucional exigiria la colocación en un ángulo metodológico o en otro según el aspecto tratado, aunque quede claro que cometido de toda ciencia social seria es la de reducir la complejidad estudiada, y no limitarse a parafrasearla, para lo cual se requieren principios de ordenación expositiva.

Por todo ello no puede dejar satisfecho el método pandiscursivo de Troper, procedente del linguistic turn de los años '60 y comprensible como un movimiento de rechazo al predominio del materialismo dialéctico en las ciencias sociales entonces vigente. Hoy bien se sabe que la historiografia es constructiva, por eso nunca puede reflejar las cosas tal y como acontecieron, pues median siempre las precomprensiones del historiador, que se interponen entre él y su objeto. Pero partir de esta premisa critica no puede conducir al escepticismo radical de que el historiador, en el fondo, solo trabaja con representaciones, y nunca con la realidad. Esta apreciación, útil para la historia del pensamiento e incluso para la de las normas, lo es mucho menos para la institucional o para la que indaga en las luchas por el poder. Y una mera consulta documental sobre procesos judiciales o expedientes gubernativos basta para aclarar que, a veces, el historiador puede reconstruir con toda la exactitud que permite el deficiente análisis racional un episodio real, a no ser, claro, que se caiga en la frivolidad pequeñoburguesa de que la realidad no existe. De hecho, si no se sucumbe a tal tentación, se podrá observar cómo, en muchas ocasiones, las representaciones doctrinales no son tanto ideas como ideologias, que, aun formando un universo 
autónomo, digno de estudio, desempeñan la función de prestar cobertura a la acción y a la lucha por el poder, mostrando con ello su posición secundaria en la reconstrucción global del constitucionalismo en la historia.

Qué es, en fin, lo que se debe identificar como objeto propio dicha de reconstrucción. Como han afirmado algunos de los autores del volumen, importan las constituciones, la legislación, los poderes estatales, esto es, los cuerpos legisladores, las administraciones públicas, la función jurisdiccional, y también los fundamentos culturales de toda esta institucionalidad. ¿Qué diferencia hay, por tanto, entre este campo de observación y el propio de la historia del Estado? Podría decirse que mientras la historia constitucional pone el énfasis en los derechos y la libertad, la historia del Estado lo hace en el poder, aunque podría replicarse que el correcto estudio de éste arroja precisamente el saldo de las libertades. Podría argumentarse también que el núcleo de la historia constitucional continúan siendo, de todos modos, las normas fundamentales, pero así se vuelve a recaer en la narrativa unidimensional que se quiere conjurar, y no se tiene en cuenta que historiar el Estado también implica encarar el objeto jurídico-constitucional, pero situándolo en un universo mayor, en el que no siempre ha tenido ni tiene la posición de causa primigenia.

Tomar como objeto la historia del Estado tiene, a mi juicio, varias ventajas: supera el frecuente riesgo de recaer en la exegética constitucional, atiende al proceso de transformación social fundamental de la modernidad, que no es otro que la estatalización de la sociedad, y, aunque nos sitúa preferentemente en la contemporaneidad, nos permite integrar, incluso como negaciones del Estado, las decisivas experiencias dictatoriales. Por otro lado, siendo la forma-Estado la que terminó estructurando casi todo el espacio político mundial a lo largo del siglo $\mathrm{XIX}^{14}$, puede constituir una útil plataforma para colocarse en la última estación del comparatismo historiográfico: la historia global ${ }^{15}$. Pero el Estado no es, desde luego, un dispositivo impersonal, neutro, ajeno a la distribución del poder social. Por eso su tratamiento histórico es inseparable del análisis de la lucha por el poder, siendo de hecho uno de los instrumentos más preciosos y potentes en dicha confrontación, toda vez que el sector parcial que se apodere de sus instituciones, o predomine en ellas, logrará hacer pasar, coacción mediante, como universal o general lo que, en realidad, solo tiene entidad particular ${ }^{16}$.

Si en el volumen que terminamos ahora de comentar se contiene un ejemplo práctico valioso de este punto de vista es, a mi juicio, el desmitificador relato de Vice sobre los motivos inspiradores de la revolución norteamericana. Bien cierto es, de todos modos, que objeto tan extenso como el Estado se hace dificilmente abarcable para un relato de conjunto; es ahí donde han de entrar en juego los consejos tipológicos de Fioravanti o el concepto de "principio estructural" empleado por Varela entendido "como conjunto de preceptos que delimitan la forma de Estado" (p. 28, n. 30), pues se trata, no de realizar un mapa a escala

14 Tal es la tesis de Christopher A. Bayly, El nacimiento del mundo moderno, 1780-1914, Siglo XXI, Madrid, 2010.

15 Thomas Duve (ed.), Entanglements in Legal History: Conceptual Approaches, Max Planck Institut für europäische Rechtsgeschichte, Frankfurt am Main, 2014.

16 Son valiosas las reflexiones al respecto de Pierre Bourdieu, Sobre el Estado, Anagrama, Barcelona, 2014. 
1:1, sino de hallar los principios sintéticos que han ido jalonando la construcción del Estado.

Fecha de envío / Submission Date: 23/05/2015

Fecha de aceptación / Acceptance Date: 4/06/2015 